STUDI

FRANCESI
Studi Francesi

Rivista quadrimestrale fondata da Franco Simone

180 (LX | III) | 2016

Varia

\title{
Les poètes français de la Renaissance et leurs «libraires», éd. Denis Bjaï et François Rouget
}

Sabine Lardon

\section{(2) OpenEdition}

Journals

\section{Édition électronique}

URL : http://journals.openedition.org/studifrancesi/5304

DOI : 10.4000/studifrancesi.5304

ISSN : 2421-5856

Éditeur

Rosenberg \& Sellier

\section{Édition imprimée}

Date de publication : 1 décembre 2016

Pagination : 520-521

ISSN : 0039-2944

\section{Référence électronique}

Sabine Lardon, « Les poètes français de la Renaissance et leurs «libraires», éd. Denis Bjaï et François Rouget », Studi Francesi [En ligne], 180 (LX | III) | 2016, mis en ligne le 01 janvier 2017, consulté le 18 septembre 2020. URL : http://journals.openedition.org/studifrancesi/5304 ; DOI : https://doi.org/ 10.4000/studifrancesi.5304

Ce document a été généré automatiquement le 18 septembre 2020.

\section{(c) $($ ) $\odot$}

Studi Francesi è distribuita con Licenza Creative Commons Attribuzione - Non commerciale - Non opere derivate 4.0 Internazionale. 


\title{
Les poètes français de la Renaissance et leurs «libraires», éd. Denis Bjaï et François Rouget
}

\author{
Sabine Lardon
}

\section{RÉFÉRENCE}

Les poètes français de la Renaissance et leurs «libraires», édité par Denis BJAÏ et François ROUGET, Genève, Droz, 2015.

1 Cet ouvrage, préfacé et édité par Denis Bajï et François Rouget, réunit les actes du colloque international qui s'est déroulé à Orléans du 5 au 7 juin 2013.

2 La première partie, «Stratégies éditoriales et création poétique», présente les stratégies mises en place aussi bien par les auteurs que par les libraires pour imprimer et diffuser les œuvres. Michèle CLÉMENT (Les poètes et les libraires au prisme du privilège d'auteur au XVI siècle: la proto-propriété littéraire, pp. 15-54) s'intéresse aux premiers privilèges pour se demander dans quelle mesure ils peuvent marquer la naissance d'un droit de l'auteur conquis sur le libraire. Isabelle PANTIN (Innovation poétique, innovation typographique: comment penser un synchronisme?, pp. 55-76) se concentre pour sa part sur l'évolution de la page du livre de poésie de la fin du $\mathrm{Xv}^{\mathrm{e}} \mathrm{s}$. à l'avènement de la Pléiade afin de suivre le lien entre innovation typographique et innovation poétique. Jean BALSAMO (Les libraires $d u$ Palais et les poètes (1530-1610), pp. 77-99) observe le milieu spécifique des libraires du palais et les nouveautés de leurs choix éditoriaux (traductions, séries...). François ROUGET (Philippe Desportes et ses libraires, pp. 101-119) se place à l'inverse du point de vue de l'auteur, pour étudier, à travers Philippe Desportes, les motifs qui l'ont amené à choisir ses imprimeurs-libraires (Robert Estienne puis Raphaël du Petit-Val en particulier).

3 Deuxième partie, «"La Pléiade" et ses libraires», se consacre au lien entre les auteurs de la Pléiade et le milieu éditorial. Geneviève GUILLEMINOT-CHRÉTIEN (Ronsard, Baif et la veuve 
Maurice de La Porte: une nouvelle présentation du recueil poétique, pp.123-134) observe l'interaction entre les choix des poètes et des libraires dans l'évolution de l'ornementation de la page poétique dans les années 1550. Daniel MÉNAGER (Ronsard, Henri Estienne et Anacréon, pp. 135-147) relève le cas «aussi célèbre qu'insolite» (pp. 146) que constitue l'édition des odes d'Anacréon par Henri Estienne, partant de l'hommage que lui rend Ronsard pour considérer ensuite son discours paratextuel. Emmanuel BURON (La pratique du poème liminaire comme analyse pragmatique de l'acte éditorial: Jodelle, Étienne Groulleau et André Wechel, pp. 149-172) s'intéresse pour sa part à un autre cas insolite, celui, paradoxal, d'Étienne Jodelle qui, s'il refuse de publier son œuvre, contribue par ailleurs au paratexte de plusieurs publications, contribution motivée tout particulièrement par les liens que Jodelle entretient avec deux libraires: Étienne Groulleau et André Wechel.

4 La troisième partie, "Poètes de province et ambitions éditoriales», se projette sur le milieu éditorial de province. Denis BJAÏ (Un imprimeur orléanais de la Renaissance et "ses" poètes: autour d'Eloi Gibier (1551-c.1587), pp.175-209) rend hommage aux presses orléanaises en présentant les activités d'Eloi Gibier. Nicolas DUCIMETIÈRE (Coups d'essai: les étudiants poètes et leurs imprimeurs-libraires dans la seconde moitié $d u \mathrm{xvI}^{\mathrm{e}}$ siècle, pp. 211-255) observe les motivations et les stratégies de publication des jeunes poètes débutants et leurs liens avec les imprimeurs-libraires. Anne RÉACH-NGÔ (Des Trésors poétiques à la Renaissance? L'ambition éditoriale du "Trésor immortel" de Jacques Sireulde, pp. 257-276) met en regard les deux seuls recueils poétiques de l'époque à porter le titre de Trésor pour en évaluer la stratégie éditoriale. Christine BÉNÉVENT présente la stratégie éditoriale de l'auteur occitan du recueil Lou Banquet (Auger Gaillard: les tribulations d'un poète en quête de libraire(s), pp. 277-308).

5 La quatrième partie, «Les libraires lyonnais et leurs poètes», est consacrée au milieu lyonnais. François RIGOLOT (D'un libraire à l'autre: Marot, de Tory à Dolet via Montmorency, p.311-335) suit l'itinéraire éditorial de Marot, de Tory dont les innovations typographiques s'accordent avec la "conscience d'auteur» du poète, à Dolet auquel il confie l'édition de ses CEuvres en 1538. Mireille HUchon (Jean de Tournes et ses "poetrices", pp. 337-357) s'intéresse à la place des poetrices, Pernette du Guillet et Louise Labé, dans la stratégie éditoriale de Jean de Tournes. Elise RAJCHENBACH-TELLER (Charles Fontaine: le poète et ses imprimeurs-libraires, pp. 359-379) enfin montre comment Charles Fontaine travaille en étroite collaboration avec les imprimeurs-libraires.

6 Dans la cinquième partie, «Les poètes chrétiens et leurs libraires», Max ENGAMMARE (Théodore de Bèze poète et ses imprimeurs, pp.383-406) nous fait suivre l'itinéraire éditorial de Théodore de Bèze, de Conrad Badius à Henri Estienne. Véronique FERRER (Entre La Rochelle et Genève: les poètes protestants et leurs imprimeurs (1560-1610), pp. 407-419) confronte les deux grands pôles éditoriaux protestants, La Rochelle et Genève, afin de dégager leurs convergences ou spécificités. Yvonne BELLENGER (Du Bartas et ses libraires, pp.421-432) retrace l'histoire éditoriale complexe des œuvres bartasiennes et Alain CULLIÈRE (Les éditeurs des "Dévots élancements du poète chrétien" d'Alphonse de Rambervillers (1602-1617), pp.433-452) celle de l'œuvre spirituelle d'Alphonse de Rambervillers, qui présente l'originalité d'accorder une place importante aux images dans un recueil de spiritualité.

7 Dans la sixième et dernière partie enfin, «Poètes humanistes et transmissions éditoriales», Michel MAGNIEN (Vascosan éditeur de Guillaume Du Mayne (1556), pp. 455-483) 
donne ici une place à Vascosan, plus connu pour ses éditions humanistes, à travers l'impression groupée de trois recueils poétiques d'un même auteur en 1556. Philippe DESAN (La Boétie poète et ses deux éditeurs: Frederic Morel et Montaigne, pp. 485-505) dégage les enjeux politiques de la stratégie éditoriale des œuvres de La Boétie. John NASSICHUK (L'œuvre latin de Jean Rouxel et le monde de l'édition en Normandie, p. 507-527) étudie la publication de la paraphrase latine des Lamentations par l'humanistes caennais Jean Rouxel.

8 Complété par un index nominum, cet ouvrage propose un riche panorama des liens qu'entretiennent, au fil du siècle, poètes et imprimeurs-libraires, considérant aussi bien les stratégies éditoriales des professionnels de l'édition et des poètes, que les différents milieux éditoriaux ou encore les innovations typographiques. 